\title{
Invasive Cancer Incidence and Survival — United States, 2013
}

\author{
S. Jane Henley, MSPH${ }^{1}$; Simple D. Singh, MD ${ }^{1}$; Jessica King, $\mathrm{MPH}^{1}$; Reda J. Wilson, MPH${ }^{1}$; Mary Elizabeth O’Neil, MPH ${ }^{1}$; A. Blythe Ryerson, PhD ${ }^{1}$
}

Although cancer represents many heterogeneous diseases, some cancer types share common risk factors. For example, conclusive evidence links cancer at multiple sites with tobacco use, alcohol use, human papillomavirus (HPV) infection, excess body weight, and physical inactivity $(1,2)$. To monitor changes in cancer incidence and assess progress toward achieving Healthy People 2020 objectives, ${ }^{*}$ CDC analyzed data from the U.S. Cancer Statistics (USCS) data set for 2013, the most recent year for which incidence and survival data are available. In 2013, a total of 1,559,130 invasive cancers were reported to cancer registries in the United States (excluding Nevada), for an annual age-adjusted incidence rate of 439 cases per 100,000 persons. Cancer incidence rates were higher among males (479) than females (413), highest among blacks (444), and ranged by state from 364 (New Mexico) to 512 (Kentucky) per 100,000 persons (359 in Puerto Rico). The proportion of persons with cancer who survived $\geq 5$ years after diagnosis was $67 \%$. This proportion was the same for males and females (67\%), but lower among blacks (62\%) than among whites (67\%). Cancer surveillance data are key to cancer epidemiologic and clinical outcomes research, program planning and monitoring, resource allocation, and state and federal appropriations accountability.

The USCS data set is a compilation of data from multiple sources and is used to report official federal cancer statistics through the USCS web-based report. USCS includes high quality incidence data from population-based cancer registries affiliated with CDC's National Program of Cancer Registries (NPCR) and the National Cancer Institute's (NCI's) Surveillance, Epidemiology, and End Results (SEER) program in each state, the District of Columbia (DC), and Puerto Rico;

\footnotetext{
*As of 2017, Healthy People 2020 objectives included improving the proportion of persons surviving $\geq 5$ years after cancer diagnosis to $71.7 \%$, reducing colorectal cancer incidence to 39.9 per 100,000 persons, reducing late-stage breast cancer incidence to 42.1 per 100,000 females, and reducing cervical cancer incidence to 7.2 per 100,000 females (https://www.healthypeople.gov/2020/ topics-objectives).
}

survival data from NPCR; and mortality data from the National Vital Statistics System (3,4). This report includes data on new cases of invasive cancer diagnosed in 2013 (the most recent year with data available); invasive cancers are all cancers excluding in situ cancers (except in the urinary bladder) and basal and squamous cell skin cancers. Data from DC and all states except Nevada met USCS publication criteria for $2013^{\dagger}$;

\footnotetext{
$\dagger$ Cancer registries demonstrated that cancer incidence data were of high quality by meeting the six USCS publication criteria: 1) case ascertainment $\geq 90 \%$ complete; 2) $\leq 5 \%$ of cases ascertained solely on the basis of death certificate; 3 ) $\leq 3 \%$ of cases missing information on sex; 4 ) $\leq 3 \%$ of cases missing information on age; 5 ) $\leq 5 \%$ of cases missing information on race; and 6) $\geq 97 \%$ of registry's records passed a set of single-field and interfield computerized edits that test the validity and logic of data components (https://www.cdc.gov/cancer/npcr/ uscs/index.htm).
}

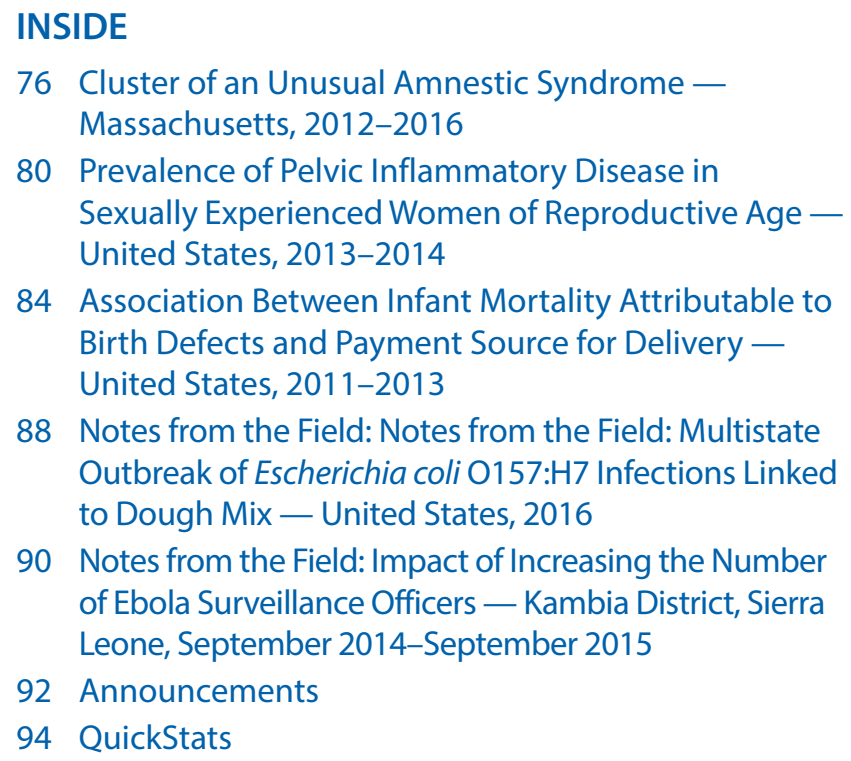

88 Notes from the Field: Notes from the Field: Multistate Outbreak of Escherichia coli 0157:H7 Infections Linked to Dough Mix — United States, 2016

90 Notes from the Field: Impact of Increasing the Number of Ebola Surveillance Officers - Kambia District, Sierra Leone, September 2014-September 2015

92 Announcements

94 QuickStats

Continuing Education examination available at https://www.cdc.gov/mmwr/cme/conted_info.html\#weekly.

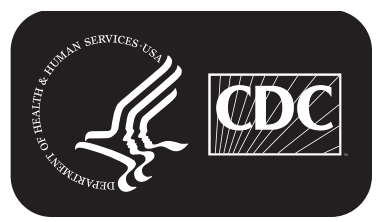

U.S. Department of Health and Human Services Centers for Disease Control and Prevention 
consequently, incidence data in this report cover $99 \%$ of the U.S. population. For comparability with past estimates, data for the United States were restricted to the states and DC, and data for Puerto Rico were analyzed separately. Cases were classified first by anatomic site, using the International Classification ofDiseases for Oncology, Third Edition. ${ }^{\S}$ Cases with hematopoietic histologies were classified further, using the World Health Organization Classification of Tumours of Haematopoietic and Lymphoid Tissues, Fourth Edition. Breast cancers were characterized by stage at diagnosis using SEER Summary Staging Manual 2000**; late-stage cancers include those diagnosed after they had spread regionally or metastasized. To characterize the potential cancer prevalence associated with common risk factors, cancer sites were grouped by association with tobacco use, alcohol use, or HPV infection. ${ }^{\dagger \dagger}$ Population denominators for incidence rates were annual race-, ethnicity-, and sexspecific county population estimates from the U.S. Census, as modified by $\mathrm{NCI}$ and aggregated to the state and national

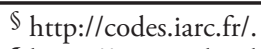

Sttps://www.ncbi.nlm.nih.gov/pmc/articles/PMC3109529/.

** https://seer.cancer.gov/tools/ssm.

†† Tobacco-associated cancers include cancers of the oral cavity and pharynx; esophagus; stomach; colon and rectum; liver; pancreas; larynx; lung, bronchus, and trachea; cervix; kidney and renal pelvis; urinary bladder; and acute myeloid leukemia. Alcohol-associated cancers include cancers of the oral cavity and pharynx; esophagus; colon and rectum; liver; larynx; and female breast. HPV-associated cancers include microscopically confirmed carcinoma of the cervix and squamous cell carcinomas of the vagina, vulva, penis, anus, rectum, and oropharynx.
}

level. ${ }^{\$ \$}$ Annual incidence rates per 100,000 population were age-adjusted to the 2000 U.S. standard population.

Survival estimates were based on data from NPCR-funded states that met USCS publication criteria and conducted active case follow-up or linkage with CDC's National Center for Health Statistics National Death Index (5). For this report, 29 states met these criteria, covering $66 \%$ of the U.S. population. The 5-year relative survival proportion was defined as the proportion of persons surviving $\geq 5$ years after cancer diagnosis compared with the proportion of survivors expected in a comparable group of cancer-free persons. The 5-year relative survival proportion was calculated using the Ederer II actuarial method for cases of cancer diagnosed during 2006-2012 with follow-up through 2012, accounting for shorter follow-up time of cases diagnosed in more recent diagnosis years.

In 2013, a total of 1,559,130 invasive cancers were diagnosed and reported to central cancer registries in the United States (excluding Nevada), including 781,451 among males and 777,679 among females (Table 1). The age-adjusted annual incidence for all cancers was 439 per 100,000 persons (479 in males and 413 in females). Among persons aged $<20$ years, 14,728 cancers ( 18 per 100,000 persons $<20$ years) were diagnosed in 2013 (Table 1). The cancer incidence rate increased

\footnotetext{
\$S Population estimates incorporate bridged single-race estimates derived from the original multiple race categories in the 2010 U.S. Census. https://seer. cancer.gov/popdata/index.html; http://www.census.gov/programs-surveys/ popest.html.
}

The MMWR series of publications is published by the Center for Surveillance, Epidemiology, and Laboratory Services, Centers for Disease Control and Prevention (CDC), U.S. Department of Health and Human Services, Atlanta, GA 30329-4027.

Suggested citation: [Author names; first three, then et al., if more than six.] [Report title]. MMWR Morb Mortal Wkly Rep 2017;66:[inclusive page numbers].

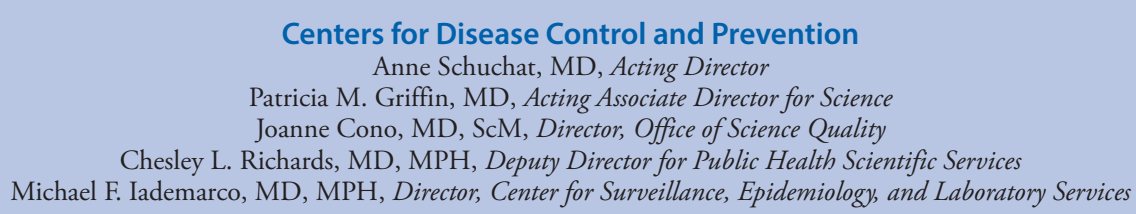

MMWR Editorial and Production Staff (Weekly)

Sonja A. Rasmussen, MD, MS, Editor-in-Chief

Charlotte K. Kent, $\mathrm{PhD}$, MPH, Executive Editor Jacqueline Gindler, MD, Editor

Teresa F. Rutledge, Managing Editor

Douglas W. Weatherwax, Lead Technical Writer-Editor

Stacy A. Benton, Soumya Dunworth, PhD, Teresa M. Hood, MS, Technical Writer-Editors

Timothy F. Jones, MD, Chairman

Matthew L. Boulton, MD, MPH

Virginia A. Caine, MD

Katherine Lyon Daniel, PhD

Jonathan E. Fielding, MD, MPH, MBA

David W. Fleming, MD
Martha F. Boyd, Lead Visual Information Specialist

Maureen A. Leahy, Julia C. Martinroe, Stephen R. Spriggs, Tong Yang, Visual Information Specialists

Quang M. Doan, MBA, Phyllis H. King,

Terraye M. Starr, Moua Yang,

Information Technology Specialists
MMWR Editorial Board

William E. Halperin, MD, DrPH, MPH

King K. Holmes, MD, PhD

Robin Ikeda, MD, MPH

Rima F. Khabbaz, MD

Phyllis Meadows, PhD, MSN, RN

Jewel Mullen, MD, MPH, MPA
Jeff Niederdeppe, $\mathrm{PhD}$

Patricia Quinlisk, MD, MPH

Patrick L. Remington, MD, MPH

Carlos Roig, MS, MA

William L. Roper, MD, MPH

William Schaffner, MD 
TABLE 1. Number and annual age-adjusted rate* of invasive cancers, ${ }^{\dagger}$ by sex, cancer site, race/ethnicity, ${ }^{\S}$ and age group — National Program of Cancer Registries and Surveillance, Epidemiology, and End Results Program, United States, " 2013

\begin{tabular}{|c|c|c|c|c|c|c|}
\hline \multirow[b]{2}{*}{ Characteristic } & \multicolumn{2}{|c|}{ Overall } & \multicolumn{2}{|c|}{ Male } & \multicolumn{2}{|c|}{ Female } \\
\hline & Rate & No. (\%) & Rate & No. (\%) & Rate & No. (\%) \\
\hline All cancer sites & 439.0 & $1,559,130(100)$ & 479.0 & $781,451(100)$ & 412.6 & $777,679(100)$ \\
\hline Prostate & NA & $176,450(11)$ & 101.6 & $176,450(23)$ & NA & NA \\
\hline Female breast & NA & $230,815(15)$ & NA & NA & 123.7 & $230,815(30)$ \\
\hline Late-stage female breast & NA & $76,816(5)$ & NA & NA & 42.1 & $76,816(10)$ \\
\hline Lung and bronchus & 59.4 & $212,584(14)$ & 69.8 & $111,907(14)$ & 51.5 & $100,677(13)$ \\
\hline Colon and rectum & 38.4 & $136,119(9)$ & 44.2 & $71,099(9)$ & 33.6 & $65,020(8)$ \\
\hline Cervix uteri & NA & $11,955(1)$ & NA & NA & 7.2 & $11,955(2)$ \\
\hline \multicolumn{7}{|l|}{ Race/Ethnicity } \\
\hline White & 439.3 & $1,304,263(84)$ & 473.9 & $654,240(84)$ & 417.4 & $650,023(84)$ \\
\hline Black & 443.6 & $170,123(11)$ & 518.6 & $85,190(11)$ & 393.6 & $84,933(11)$ \\
\hline American Indian/Alaska Native & 276.4 & $8,676(1)$ & 289.3 & $4,097(1)$ & 269.6 & $4,579(1)$ \\
\hline Asian and Pacific Islander & 284.0 & $47,802(3)$ & 290.5 & $21,052(3)$ & 283.3 & $26,750(3)$ \\
\hline Hispanic & 343.7 & $117,332(8)$ & 372.0 & $55,393(7)$ & 328.7 & $61,939(8)$ \\
\hline \multicolumn{7}{|l|}{ Age group (yrs) } \\
\hline$<20$ & 18.0 & $14,728(1)$ & 18.7 & $7,815(1)$ & 17.3 & $6,913(1)$ \\
\hline $20-49$ & 154.8 & $187,560(12)$ & 111.9 & $68,160(9)$ & 197.2 & $119,400(15)$ \\
\hline $50-64$ & 798.3 & $505,337(32)$ & 837.0 & $258,164(33)$ & 763.2 & $247,173(32)$ \\
\hline $65-74$ & $1,756.0$ & $433,944(28)$ & $2,075.9$ & $239,204(31)$ & $1,477.0$ & $194,740(25)$ \\
\hline$\geq 75$ & $2,163.1$ & $417,561(27)$ & $2,685.9$ & $208,108(27)$ & $1,813.7$ & $209,453(27)$ \\
\hline
\end{tabular}

Abbreviation: NA = not available.

* Per 100,000 persons, age-adjusted to the 2000 U.S. standard population.

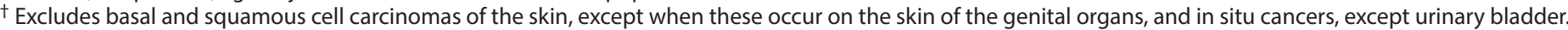

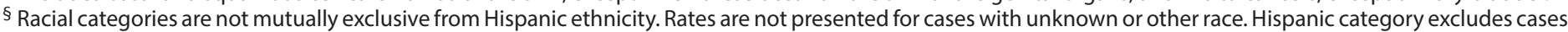
from Virginia because a large percentage of cases were missing information on ethnicity.

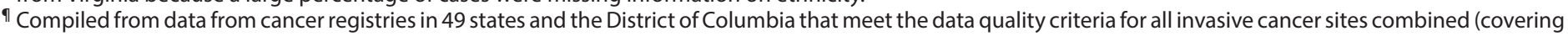
approximately $99 \%$ of the U.S. population).

with increasing age group, with highest rates $(2,163$ per 100,000 persons) among persons aged $\geq 75$ years (Table 1 ).

By cancer site, incidence rates were highest for cancers of the female breast (124 per 100,000 females); prostate (102 per 100,000 males); lung and bronchus (lung) (59 per 100,000 persons); and colon and rectum (colorectal) (38 per 100,000 persons) (Table 1). These four sites accounted for approximately half of cancers diagnosed in 2013 , including 230,815 female breast cancers, 176,450 prostate cancers, 212,584 lung cancers, and 136,119 colorectal cancers. In 2013, cervical cancer incidence was 7.2 per 100,000 females, representing 11,955 reported cancers (Table 1). The incidence (rates per 100,000 persons) for cancers associated with tobacco use, alcohol use, and HPV were 187, 130, and 11, respectively (Table 2).

By state, in 2013, age-adjusted incidence rates for cancers of all sites (all-sites cancer) ranged from 364 per 100,000 persons in New Mexico to 512 per 100,000 persons in Kentucky (Table 2). State site-specific cancer incidence rates for prostate cancer ranged from 69 (Arizona) to 131 (Louisiana) per 100,000 males; for female breast cancer, from 105 (Wyoming) to 148 (New Hampshire) per 100,000 females; for lung cancer, from 26 (Utah) to 93 (Kentucky) per 100,000 persons; for colorectal cancer, from 32 (Arizona, New Mexico, Utah, and Vermont) to 49 (Kentucky and Mississippi) per 100,000 persons; and for cervical cancer, from four (New Hampshire and Montana) to
11 (Arkansas) per 100,000 females (Table 2). The Healthy People 2020 target for reducing colorectal cancer incidence to $\leq 39.9$ per 100,000 persons was reached in 30 states and the target for reducing cervical cancer incidence to $\leq 7.2$ per 100,000 females was reached in 28 states. For grouped cancers, incidence rates for tobacco-related cancers ranged by state from 128 (Utah) to 245 (Kentucky) per 100,000 persons; for alcohol-related cancers, from 107 (Wyoming) to 146 (Kentucky) per 100,000 persons; and for HPV-related cancers, from seven (Utah) to 14 (Arkansas and Kentucky) per 100,000 persons (Table 2). Compared with the states and DC, cancer incidence rates in Puerto Rico in 2013 were lower for all-sites cancer (359 per 100,000 persons), lung cancer (18 per 100,000 persons), and female breast cancer (96 per 100,000 females), but higher for prostate cancer ( 145 per 100,000 males), colorectal cancer ( 42 per 100,000 persons), and cervical cancer (12 per 100,000 females) (Table 2).

Among persons with cancer diagnosed during 2006-2012, the 5 -year relative survival proportion was $67 \%$ (Table 3 ). This proportion was similar for males and females. The 5-year relative survival proportion was highest among persons who received a diagnosis of cancer before age 45 years (83\%) and decreased with increasing age (Table 3 ). Among the four most common cancer sites, the 5-year relative survival proportion was highest for prostate cancer (99\%) and female breast cancer (90\%), intermediate for colorectal cancer (66\%), and lowest 
TABLE 2. Annual age-adjusted rate* of invasive cancers, ${ }^{\dagger}$ by cancer site and state - National Program of Cancer Registries and Surveillance, Epidemiology, and End Results program, United States, 2013

\begin{tabular}{|c|c|c|c|c|c|c|c|c|c|}
\hline \multirow[b]{2}{*}{ State } & \multicolumn{6}{|c|}{ Cancer site } & \multicolumn{3}{|c|}{$\begin{array}{c}\text { Cancers associated } \\
\text { with certain risk factors } \S\end{array}$} \\
\hline & All sites & $\begin{array}{l}\text { Lung and } \\
\text { bronchus }\end{array}$ & $\begin{array}{l}\text { Colon and } \\
\text { rectum }\end{array}$ & Prostate & Female breast & Cervix & Tobacco use & Alcohol use & HPV \\
\hline Alabama & 444.0 & 66.7 & 44.0 & 118.5 & 120.6 & 8.5 & 202.5 & 137.3 & 12.5 \\
\hline Alaska & 410.4 & 54.7 & 43.0 & 76.6 & 120.5 & 6.6 & 187.2 & 130.0 & 11.6 \\
\hline Arizona & 370.6 & 48.4 & 32.1 & 69.1 & 110.9 & 6.3 & 159.2 & 112.8 & 8.7 \\
\hline Arkansas & 454.0 & 78.7 & 43.1 & 102.7 & 118.2 & 10.6 & 215.4 & 133.4 & 14.4 \\
\hline California & 402.8 & 42.6 & 35.1 & 97.5 & 120.9 & 7.0 & 159.9 & 123.4 & 10.0 \\
\hline Colorado & 396.1 & 42.2 & 33.6 & 101.6 & 123.6 & 5.7 & 152.3 & 120.5 & 9.2 \\
\hline Connecticut & 474.2 & 62.3 & 36.3 & 104.6 & 138.4 & 7.3 & 196.1 & 136.4 & 11.6 \\
\hline Delaware & 502.0 & 69.1 & 34.9 & 129.4 & 144.8 & 6.7 & 203.8 & 142.5 & 11.9 \\
\hline District of Columbia (DC) & 445.2 & 55.3 & 41.4 & 120.1 & 138.2 & 8.3 & 181.4 & 144.0 & 13.0 \\
\hline Florida & 413.0 & 58.8 & 35.8 & 86.4 & 114.1 & 8.4 & 179.0 & 123.4 & 13.4 \\
\hline Georgia & 450.3 & 64.0 & 40.7 & 117.7 & 123.2 & 6.9 & 190.3 & 133.5 & 12.1 \\
\hline Hawaii & 419.8 & 49.3 & 41.8 & 79.2 & 143.9 & 6.5 & 176.1 & 144.7 & 8.5 \\
\hline Idaho & 419.5 & 46.9 & 35.1 & 101.4 & 119.4 & 5.2 & 169.1 & 120.8 & 10.5 \\
\hline Illinois & 454.9 & 63.2 & 43.0 & 105.3 & 130.1 & 7.2 & 200.1 & 138.4 & 11.6 \\
\hline Indiana & 438.8 & 71.6 & 42.1 & 85.7 & 120.4 & 7.6 & 205.2 & 132.0 & 12.4 \\
\hline lowa & 456.1 & 62.0 & 42.9 & 96.9 & 118.4 & 5.7 & 195.3 & 132.2 & 11.6 \\
\hline Kansas & 450.9 & 61.8 & 38.6 & 108.5 & 115.6 & 7.1 & 189.6 & 125.3 & 10.8 \\
\hline Kentucky & 511.7 & 93.4 & 49.0 & 104.8 & 123.2 & 7.9 & 244.5 & 146.1 & 14.1 \\
\hline Louisiana & 476.3 & 68.0 & 45.0 & 131.2 & 124.6 & 8.2 & 215.0 & 142.6 & 12.7 \\
\hline Maine & 463.8 & 74.8 & 37.4 & 80.7 & 126.0 & 5.9 & 203.0 & 130.1 & 12.4 \\
\hline Maryland & 451.0 & 56.6 & 35.8 & 124.4 & 134.1 & 5.9 & 180.3 & 133.6 & 9.8 \\
\hline Massachusetts & 457.5 & 62.6 & 36.4 & 97.2 & 137.2 & 4.9 & 192.7 & 137.7 & 10.8 \\
\hline Michigan & 440.1 & 62.4 & 36.7 & 102.8 & 124.8 & 6.7 & 189.0 & 128.0 & 10.8 \\
\hline Minnesota & 451.8 & 56.6 & 38.7 & 101.6 & 127.9 & 5.3 & 180.6 & 129.9 & 9.4 \\
\hline Mississippi & 459.9 & 75.2 & 48.7 & 127.2 & 112.3 & 8.1 & 218.7 & 139.2 & 13.0 \\
\hline Missouri & 442.6 & 73.7 & 41.0 & 84.7 & 124.9 & 7.7 & 204.9 & 134.8 & 12.4 \\
\hline Montana & 437.0 & 58.0 & 38.8 & 108.0 & 109.4 & 4.1 & 180.0 & 119.1 & 9.0 \\
\hline Nebraska & 437.6 & 60.1 & 39.9 & 106.1 & 118.7 & 7.4 & 184.3 & 125.1 & 10.1 \\
\hline Nevada & - & — & — & - & - & - & - & —? & — \\
\hline New Hampshire & 479.2 & 64.8 & 37.0 & 115.6 & 148.4 & 3.6 & 192.0 & 140.3 & 10.2 \\
\hline New Jersey & 483.1 & 57.5 & 41.9 & 123.4 & 135.5 & 7.5 & 193.1 & 139.6 & 10.9 \\
\hline New Mexico & 363.7 & 39.6 & 32.1 & 80.9 & 112.6 & 7.2 & 148.3 & 115.7 & 9.0 \\
\hline New York & 484.3 & 59.5 & 39.3 & 125.6 & 130.3 & 8.0 & 196.2 & 135.7 & 11.2 \\
\hline North Carolina & 445.4 & 68.5 & 36.3 & 107.8 & 126.1 & 6.6 & 194.5 & 131.4 & 11.7 \\
\hline North Dakota & 433.6 & 56.4 & 46.0 & 100.5 & 125.5 & - ${ }^{* *}$ & 183.8 & 132.3 & 8.8 \\
\hline Ohio & 452.4 & 67.4 & 40.6 & 101.7 & 125.8 & 7.4 & 200.3 & 134.3 & 12.1 \\
\hline Oklahoma & 440.3 & 68.7 & 42.5 & 95.0 & 117.0 & 9.5 & 203.0 & 132.7 & 13.0 \\
\hline Oregon & 431.5 & 55.6 & 34.5 & 88.7 & 124.8 & 6.7 & 179.9 & 126.8 & 12.1 \\
\hline Pennsylvania & 483.0 & 64.3 & 42.3 & 101.2 & 130.8 & 7.1 & 204.6 & 139.8 & 11.8 \\
\hline Rhode Island & 479.4 & 69.9 & 35.4 & 91.1 & 137.8 & 7.4 & 206.5 & 136.3 & 12.1 \\
\hline South Carolina & 436.9 & 64.4 & 36.1 & 105.8 & 124.5 & 7.7 & 191.3 & 130.7 & 13.2 \\
\hline South Dakota & 450.1 & 59.4 & 40.8 & 102.1 & 146.1 & 7.3 & 183.3 & 139.1 & 11.5 \\
\hline Tennessee & 450.9 & 74.1 & 38.2 & 106.2 & 124.6 & 8.9 & 203.0 & 133.4 & 13.3 \\
\hline Texas & 399.4 & 52.7 & 37.4 & 88.6 & 108.4 & 8.7 & 177.5 & 122.4 & 10.5 \\
\hline Utah & 393.2 & 26.1 & 32.0 & 111.9 & 111.0 & 4.8 & 128.1 & 107.5 & 7.2 \\
\hline Vermont & 437.1 & 59.1 & 31.7 & 81.7 & 125.6 & 5.7 & 176.7 & 123.5 & 10.4 \\
\hline Virginia & 418.5 & 58.2 & 35.4 & 101.0 & 128.3 & 5.8 & 175.5 & 128.3 & 10.0 \\
\hline Washington & 450.3 & 55.0 & 35.3 & 107.3 & 135.3 & 6.7 & 179.9 & 132.8 & 10.8 \\
\hline West Virginia & 464.0 & 79.1 & 47.0 & 90.3 & 116.5 & 8.1 & 223.0 & 137.1 & 12.9 \\
\hline Wisconsin & 451.1 & 59.0 & 36.4 & 103.4 & 128.6 & 5.5 & 187.5 & 129.5 & 9.7 \\
\hline Wyoming & 382.0 & 38.7 & 32.5 & 97.9 & 105.0 & 6.0 & 145.9 & 106.7 & 8.3 \\
\hline Puerto Rico (PR) & 358.5 & 18.2 & 42.0 & 144.9 & 95.8 & 12.3 & 124.3 & 117.4 & 12.3 \\
\hline States + DC + PR & 439.0 & 58.8 & 38.5 & 102.1 & 123.4 & 7.3 & 186.2 & 130.2 & 11.3 \\
\hline States + DC & 438.0 & 59.4 & 38.4 & 101.6 & 123.7 & 7.2 & 187.0 & 130.4 & 11.2 \\
\hline
\end{tabular}

See table footnotes on page 73 . 
TABLE 2. (Continued) Annual age-adjusted rate* of invasive cancers, ${ }^{\dagger}$ by cancer site and state - National Program of Cancer Registries and Surveillance, Epidemiology, and End Results program, United States, 2013

Abbreviation: $\mathrm{HPV}=$ human papillomavirus.

* Age-adjusted to the 2000 U.S. standard population. Rates are per 100,000 persons except per 100,000 males for prostate cancer and per 100,000 females for female breast and cervical cancers.

† Excludes basal and squamous cell carcinomas of the skin, except when these occur on the skin of the genital organs, and in situ cancers, except urinary bladder.

$\S$ Tobacco-associated cancers include oral cavity and pharynx; esophagus; stomach; colon and rectum; liver; pancreas; larynx; lung, bronchus, and trachea; cervix; kidney and renal pelvis; urinary bladder; and acute myeloid leukemia. Alcohol-associated cancers include oral cavity and pharynx; esophagus; colon and rectum; liver; larynx; and female breast. HPV-associated cancers include microscopically confirmed carcinoma of the cervix and squamous cell carcinomas of the vagina, vulva, penis, anus, rectum, and oropharynx.

" Rate not shown because data did not meet publication criteria.

** Rate not shown because $<16$ cases were reported.

TABLE 3. Percentage of patients with five-year relative survival after cancer diagnosis,* by race, sex, cancer site, and age group - National Program of Cancer Registries, 29 States, 2006-2012 ${ }^{\dagger}$

\begin{tabular}{|c|c|c|c|c|c|c|c|c|c|}
\hline \multirow[b]{3}{*}{ Cancer site/Age group } & \multicolumn{9}{|c|}{ Survival (\%) } \\
\hline & \multicolumn{3}{|c|}{ All races } & \multicolumn{3}{|c|}{ Whites } & \multicolumn{3}{|c|}{ Blacks } \\
\hline & Overall & Males & Females & Overall & Males & Females & Overall & Males & Females \\
\hline All sites & 67 & 67 & 67 & 67 & 67 & 68 & 62 & 64 & 59 \\
\hline Prostate & NA & 99 & NA & NA & 99 & NA & NA & 97 & NA \\
\hline Female breast & NA & NA & 90 & NA & NA & 91 & NA & NA & 80 \\
\hline Lung and bronchus & 19 & 17 & 23 & 19 & 17 & 23 & 17 & 14 & 20 \\
\hline Colon and rectum & 66 & 65 & 66 & 66 & 66 & 67 & 59 & 58 & 61 \\
\hline Cervix uteri & NA & NA & 69 & NA & NA & 70 & NA & NA & 59 \\
\hline \multicolumn{10}{|l|}{ Age group (yrs) $)^{\S}$} \\
\hline$<45$ & 83 & 78 & 85 & 84 & 80 & 87 & 72 & 67 & 75 \\
\hline $45-54$ & 74 & 69 & 78 & 75 & 70 & 80 & 65 & 63 & 66 \\
\hline $55-64$ & 71 & 70 & 71 & 71 & 70 & 72 & 64 & 67 & 61 \\
\hline $65-74$ & 66 & 69 & 63 & 67 & 69 & 64 & 62 & 67 & 54 \\
\hline$\geq 75$ & 53 & 56 & 50 & 53 & 55 & 51 & 46 & 52 & 42 \\
\hline
\end{tabular}

Abbreviation: $\mathrm{NA}=$ not applicable.

* Based on cases of cancer diagnosed during 2006-2012 and follow-up of patients through 2012.

† Compiled from data from 29 cancer registries that met data quality criteria for survival analysis, covering approximately $66 \%$ of the U.S. population.

$\S$ Age at cancer diagnosis.

for lung cancer (19\%) (Table 3). The 5-year relative survival proportion after any cancer diagnosis was lower among blacks $(62 \%)$ than among whites (67\%), particularly among black females (59\%) compared with white females (68\%) (Table 3).

\section{Discussion}

This report provides estimates of cancer incidence for 2013 in the United States and indicates that national Healthy People 2020 targets were achieved in 30 states for reduced colorectal cancer incidence and 28 states for reduced cervical cancer incidence. Many cancers could be prevented by implementing evidencebased interventions to reduce cancer risk factors, promote healthy living, and encourage appropriate cancer screening ( $\sigma$ ).

Some cancer risk factors can be addressed through clinical preventive services. As of 2016, the U.S. Preventive Services Task Force recommends that all adults be screened for tobacco use and excessive alcohol use and offered counseling and intervention as needed.99 The U.S. Preventive Services Task Force also recommends the use of low-dose aspirin to prevent colorectal cancer and cardiovascular disease among adults who

\footnotetext{
99 https://www.uspreventiveservicestaskforce.org/Page/Name/recommendations.
}

are considered to be at high risk for cardiovascular disease based on specific criteria (7). As of 2016, the Advisory Committee on Immunization Practices recommends vaccination against two cancer-causing viruses, HPV and hepatitis B virus. ${ }^{* * *}$ Health care providers play an important role in ensuring that all children, adolescents, and adults receive the preventive services they need at the appropriate time. The Community Preventive Services Task Force offers evidence-based recommendations to increase both patient and provider adherence to guidelines for preventive services as well as community-based approaches to promote physical activity, reduce excessive alcohol use, and reduce tobacco use and tobacco smoke exposure. ${ }^{\dagger \dagger \dagger}$

Cancer incidence and survival data are important for guiding the planning and evaluation of cancer prevention and control programs at the national and local levels. For example, Pennsylvania Cancer Registry data were used to guide community outreach programs in areas with cancer-related health disparities and evaluate the impact of cancer interventions (8). These data also assist long-term planning for cancer diagnostic

\footnotetext{
*** https://www.cdc.gov/vaccines/hcp/acip-recs/vacc-specific/hpv.html https://www.cdc.gov/vaccines/hcp/acip-recs/vacc-specific/hepb.html.

t† https://www.thecommunityguide.org/topic/cancer.
} 
and treatment services. By examining prostate cancer treatment data, the New Hampshire State Cancer Registry found promising trends in the management of prostate cancer, with increasing use of surgical procedures for men at high risk for the disease and less aggressive treatment for men at low risk for the disease (9). Finally, these data help public health officials set priorities for allocating health resources. The Oregon Health Authority's decision to increase measures to improve $\mathrm{HPV}$ vaccination coverage was based in part on data from the Oregon State Cancer Registry that indicated a recent increase in HPV-associated cancer incidence had occurred (10).

CDC annually provides cancer surveillance data via several products such as USCS, CDC WONDER, State Cancer Facts, and the CDC Chronic Disease Indicators web tool, and through the CDC's National Center for Health Statistics Research Data Center. ${ }^{\$ \$ \$}$ Although cancer mortality data sets formatted for use with NCI SEER*Stat software have been available since 2003, for the first time, CDC is releasing a public use NPCR cancer incidence data set that can be analyzed using the NCI SEER*Stat software; information about this data set, including variable formats for cancer groups related to tobacco use, alcohol use, HPV, obesity, and physical activity, is available online. 999

The findings in this report are subject to at least four limitations. First, analyses based on race/ethnicity might be biased if race/ethnicity was systematically misclassified; ongoing procedures are used to ensure that this information is as accurate as possible (4). Second, delays in cancer reporting might result in an underestimation of certain cancers; reporting delays are more common for cancers such as melanoma and prostate cancer that are diagnosed and treated in nonhospital settings such as physicians' offices. Third, relative survival could only be calculated for white and black racial groups because accurate life tables were not available for other racial/ ethnic groups. Finally, because information about risk factors is not routinely collected by cancer registries, estimates for risk factor-associated cancers depict the number potentially associated, not the number definitively attributable.

Public health officials use population-based cancer incidence, mortality, and survival surveillance data to plan and monitor programs, conduct clinical outcomes research, help make decisions about allocating resources, and hold recipients of state and federal appropriations accountable. To achieve the national cancer objectives set forth in Healthy People 2020, initiatives to promote healthy living, reduce exposure to cancer risk factors, improve adherence to cancer screening recommendations, and

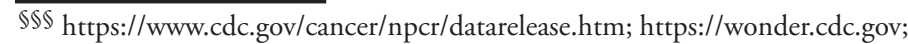
https://www.statecancerprofiles.cancer.gov/incidencerates/; https://www.cdc. gov/rdc/b1datatype/dt131.htm; https://www.cdc.gov/cdi.

999 https://www.cdc.gov/cancer/npcr/public-use.
}

\section{Summary \\ What is already known about this topic?}

Some risk factors, such as tobacco use, alcohol use, excess body weight, physical inactivity, and human papillomavirus (HPV) infection increase the risk for more than one type of cancer.

What is added by this report?

Based on the U.S. Cancer Statistics dataset, in 2013 (the most recent year for which incidence and survival data are available), a total of 1,559,130 new invasive cancers were diagnosed in the United States (excluding Nevada), for an annual incidence of 479 per 100,000 males and 413 per 100,000 females. All-sites cancer incidence rates ranged, by state, from 364 to 512 per 100,000 persons, and the rate was 359 per 100,000 persons in Puerto Rico. Healthy People 2020 targets for reducing incidence rates were reached in 30 states for colorectal cancer and 28 states for cervical cancer. Approximately two of three persons survived $\geq 5$ years after cancer diagnosis.

What are the implications for public health practice?

Cancer surveillance data are key to cancer epidemiologic and clinical outcomes research, program planning and monitoring, resource allocation, and state and federal appropriations accountability. To achieve the national cancer objectives set forth in Healthy People 2020, initiatives to promote healthy living, reduce exposure to cancer risk factors, improve adherence to cancer screening recommendations, and assure timely and appropriate clinical preventive services and treatment for all persons must be maximized. The impact of these initiatives can be monitored using publicly available cancer surveillance data.

assure timely and appropriate clinical preventive services for all persons should be maximized. The effects of these initiatives can be monitored using cancer surveillance data.

\section{Acknowledgment}

State, regional, and Puerto Rico cancer registry personnel.

\footnotetext{
${ }^{1}$ Division of Cancer Prevention and Control, National Center for Chronic Disease Prevention and Health Promotion, CDC.

Corresponding author: S. Jane Henley, shenley@cdc.gov, 770-488-4157.
}

\section{References}

1. Cogliano VJ, Baan R, Straif K, et al. Preventable exposures associated with human cancers. J Natl Cancer Inst 2011;103:1827-39. http:// dx.doi.org/10.1093/jnci/djr483

2. World Cancer Research Fund/American Institute for Cancer Research. Food, nutrition, physical activity, and the prevention of cancer: a global perspective. Washington, DC: American Institute for Cancer Research; 2007.

3. US Cancer Statistics Working Group. United States cancer statistics: 1999-2013 cancer incidence and mortality data. Atlanta, GA: US Department of Health and Human Services, CDC, US Cancer Statistics Working Group; 2016. https://www.cdc.gov/cancer/npcr/uscs/index.htm

4. Singh SD, Henley SJ, Ryerson AB. Summary of notifiable noninfectious conditions and disease outbreaks: surveillance for cancer incidence and mortality-United States, 2011. MMWR Morb Mortal Wkly Rep 2015;62:11-51. http://dx.doi.org/10.15585/mmwr.mm6254a3 
5. Wilson RJ, Ryerson AB, Zhang K, Dong X. Relative survival analysis using the Centers for Disease Control and Prevention National Program of Cancer Registries surveillance system data, 2000-2007. J Registry Manag 2014;41:72-6.

6. Colditz GA, Wolin KY, Gehlert S. Applying what we know to accelerate cancer prevention. Sci Transl Med 2012;4:127rv4. http://dx.doi. org/10.1126/scitranslmed.3003218

7. Chubak J, Whitlock EP, Williams SB, et al. Aspirin for the prevention of cancer incidence and mortality: systematic evidence reviews for the U.S. Preventive Services Task Force. Ann Intern Med 2016;164:814-25. http://dx.doi.org/10.7326/M15-2117
8. Pennsylvania Department of Health. The burden of cancer in Pennsylvania. Harrisburg, PA: Pennsylvania Department of Health; 2015. https://smhs.gwu.edu/cancercontroltap/sites/cancercontroltap/ files/The $\% 20$ Burden $\% 20$ of $\% 20$ Cancer $\% 20$ in $\% 20$ PA.pdf

9. Ingimarsson JP, Celaya MO, Laviolette M, Rees JR, Hyams ES. Trends in initial management of prostate cancer in New Hampshire. Cancer Causes Control 2015;26:923-9. http://dx.doi.org/10.1007/s10552-015-0574-8

10. Oregon Health Authority. Human papillomavirus (HPV)-related cancers: assessment of prevention programs, policies and measures. Portland, OR: Oregon Health Authority, Public Health Division; 2014 https://public.health.oregon.gov/DiseasesConditions/ChronicDisease/ Cancer/Documents/hpv-full-report.pdf 